\title{
In search of markers of treatment failure and poor prognosis in IPAH - the value of mosaic lung attenuation pattern on thin-section CT scans
} Alla ricerca di un marker di resistenza al trattamento e prognosi infausta nell'ipertensione polmonare idiopatica (IPAH) - il valore del pattern di attenuazione a mosaico nella TAC torace a sezioni sottili

\author{
Monika Szturmowicz' ${ }^{1}$ Aneta Kacprzak ${ }^{1}$, Barbara Burakowska ${ }^{2}$, Marcin Kurzyna ${ }^{1}$, \\ Anna Fijałkowska', Iwona Bestry ${ }^{2}$, Adam Torbicki ${ }^{1}$ \\ 'Department of Internal Medicine, National Institute of Tuberculosis and Lung Diseases, Warsaw, Poland \\ ${ }^{2}$ Department of Radiology, National Institute of Tuberculosis and Lung Diseases, Warsaw, Poland
}

\begin{abstract}
Despite the development of specific therapies for pulmonary arterial hypertension (PAH) some patients fail to respond to such treatment. One of the potential reasons for the unresponsiveness to targeted therapies may be the presence of fibrous occlusion of small pulmonary veins that accompanies pre-capillary arteriopathy. This type of pathologic change is called pulmonary veno-occlusive disease (PVOD). Underdiagnosed PVOD occurs probably in 5-10\% of idiopathic pulmonary hypertension (IPAH) and in a substantial proportion of PAH related to connective tissue diseases (mainly in scleroderma). A definite diagnosis of PVOD requires histological examination of lung sample, but surgical lung biopsy in pulmonary hypertension is combined with high risk of bleeding. Thus major interest is focused on a non-invasive diagnostic approach enabling early recognition of PVOD and referral for lung transplantation. The present review is focused on the radiological features suggestive of PVOD-like vasculopathy in PAH.
\end{abstract}

Keywords: CT scan, idiopathic pulmonary hypertension, mosaic lung attenuation, pulmonary veno-occlusive disease.
RIASSUNTO

Nonostante lo sviluppo di trattamenti specifici per l'ipertensione arteriosa polmonare (PAH) alcuni pazienti non rispondono alla terapia.

Una delle possibili ragioni può essere la presenza di un'occlusione fibrotica delle piccole vene polmonari in associazione con una arteriopatia pre-capillare. Questo tipo di alterazione è denominata malattia polmonare veno-occlusiva (PVOD). Probabilmente una PVOD non diagnosticata sottende a circa il $5-10 \%$ delle forme di ipertensione polmonare idiopatica (IPAH) ed a una quota rilevante delle forme di PAH secondarie a collagenopatie (soprattutto la sclerodermia). Per una diagnosi di certezza di PVOD è necessario l'esame istologico di un campione di tessuto polmonare, ma una biopsia polmonare chirurgica nell'ipertensione polmonare è ad alto rischio di sanguinamento. Vi è quindi un grande interesse per individuare un approccio diagnostico non invasivo che permetta un riconoscimento precoce della PVOD e l'avvio al trapianto polmonare. Questa rassegna è incentrata sugli aspetti radiologici suggestivi di una vascolopatia tipo PVOD nella PAH.

\section{$\equiv$ Monika Szturmowicz}

National Institute of Tuberculosis and Lung Diseases

Plocka 26, 01-138 Warsaw, Poland

email: monika.szturmowicz@gmail.com

Data di arrivo del testo: 22/02/2010 - Accettato dopo revisione: 30/04/2010

Multidisciplinary Respiratory Medicine 2010; 5(6): 409-416 
Parole chiave: Ipertensione polmonare idiopatica, malattia polmonare veno-occlusiva, pattern di attenuazione a mosaico, TAC torace.

\section{Definition and classification of pulmonary hyper- tension}

Hemodynamic diagnosis of pulmonary hypertension $(\mathrm{PH})$ requires the presence of mean pulmonary artery pressure (mPAP) of $25 \mathrm{~mm} \mathrm{Hg}$ or higher [13]. $\mathrm{PH}$ is further characterized as pre-capillary (with pulmonary capillary wedge pressure $[\mathrm{PCWP}] \leq 15$ $\mathrm{mm} \mathrm{Hg}$ ) or post-capillary or venous (with PCWP > $15 \mathrm{~mm} \mathrm{Hg}$ ) [1-3]. PH has been divided into 5 groups depending on the underlying pathomechanism. The latest update of this classification (Table I) was in 2008 [1-3].

The common feature for group 1 , called pulmonary arterial hypertension (PAH), is pre-capillary pulmonary arteriopathy. This group includes: idiopathic $\mathrm{PAH}$, heritable $\mathrm{PAH}$, and PAH associated with: connective tissue diseases (CTD), congenital heart diseases (CHD), systemic-to-pulmonary shunts, portal hypertension, HIV, use of drugs or anorexigens and many other conditions listed in Table I.

The two entities: pulmonary veno-occlusive disease (PVOD) and pulmonary capillary hemangiomatosis (PCH) were removed from group 1 to a separate group 1', due to the different pathomechanism of pulmonary hypertension (pathologic changes localized in capillaries and in small venules, causing capillary hypertension and secondary arterial hypertension).

Group 2 is composed of $\mathrm{PH}$ as a consequence of left heart pathology.

Group 3 encompasses $\mathrm{PH}$ related to pulmonary disease leading to capillary destruction and/or hypoxic pulmonary vasoconstriction.

Group 4 consists of $\mathrm{PH}$ due to chronic thromboembolic pulmonary disease (CTEPH).

Group 5 is composed of $\mathrm{PH}$ with unclear or multifactorial mechanisms.

\section{Differential diagnosis of $\mathrm{PH}$}

The routine diagnostic procedures involved in the differential diagnosis of $\mathrm{PH}$ consist of physical examination, blood and serologic tests, chest radiogram, echocardiographic study, chest computerized tomography (CT) scan, ventilation-perfusion scintigraphy and pulmonary function tests (PFT) $[4,5]$. Right heart catheterization is not only obligatory for confirmation of $\mathrm{PH}$, but it is also a very important tool in the differential diagnosis of other forms of $\mathrm{PH}[4,5]$.

Thus $\mathrm{PH}$ related to parenchymal lung diseases and chronic obstructive pulmonary disease (COPD) is diagnosed when significant PFT abnormalities +/pathologic parenchymal changes in lung $\mathrm{CT}$ scan are found. In the case of $\mathrm{PH}$ in the course of obstructive sleep apnea, pathologic polysomnography is diagnostic.

$\mathrm{PH}$ related to left heart diseases (venous, post-capillary $\mathrm{PH}$ ) is diagnosed in the case of left heart myocardial or valvular disease with increased PCWP.
CTEPH is diagnosed in those patients with $\mathrm{PH}$ who present segmental hypoperfusion areas on lung perfusion scan (scintigraphy with high probability of pulmonary embolism). The majority of these patients have had an episode of symptomatic venous thromboembolic disease in their medical history, and in some of them intravascular filling defects can be demonstrated on chest CT angiography or arteriography [2].

PAH is diagnosed after the exclusion of the abovementioned, most frequent causes of $\mathrm{PH}$. It is the most extensively investigated group due to the possibility of specific therapeutic approaches: prostacyclin derivatives, endothelin receptor antagonists and phosphodiesterase-5 inhibitors [5-8]. Prolonged specific treatment of PAH is combined with a significant improvement of functional class, increase of exercise tolerance measured by the 6minute walking test (6MWT), a decrease in serum biomarkers of myocardial injury and decompensation (troponin, BNP, NT-proBNP) and an improvement of pulmonary hemodynamics [5,9-11]. The results of a large meta-analysis involving 3,140 patients from 21 studies, presented recently by Galié et al. [12], indicate also a positive prognostic influence of specific treatment in $\mathrm{PAH}$ (43\% reduction in mortality over 14.3 weeks).

\section{Reasons for the poor response to specific treat- ment in PAH}

Despite progress in specific treatment of $\mathrm{PAH}$, there are some patients in whom the treatment is ineffective or even combined with a worsening of clinical symptoms.

This happens most frequently in PVOD/PCH, where the presence of capillary and post-capillary occlusion causes an increase of trans-capillary pressure with signs and symptoms of pulmonary congestion [13]. Underdiagnosed PVOD occurs probably in 5$10 \%$ of IPAH [13]. The clinical presentation of such cases may be indistinguishable from IPAH, excepting for a rapid development of pulmonary edema after administration of vasodilators. Harch et al. [13] examined lung specimens available from autopsy or explantation in 14 patients with clinically diagnosed $\mathrm{PAH}$ who had failed to respond to medical therapy and found PVOD in $86 \%$ of them and "arterial-only" PAH in the remaining 14\%. Montani et al. [14] described the development of pulmonary edema (mostly with continuous intravenous epoprostenol, but also with oral bosentan and calcium channel blockers) in $7 / 16$ patients with pathologically proved PVOD (43.8\%) at a median of 9 days after treatment initiation.

The definite diagnosis of PVOD/PCH requires a pathologic examination of lung tissue. Lung biopsy is contraindicated in the majority of patients with $\mathrm{PH}$, due to the possibility of life-threatening bleeding $[15,16]$. Thus pathologic material is usually obtained from explanted lung or - unfortunately during autopsy.

In PVOD fibrous venules remodeling with secondary capillary proliferation, pulmonary hemosidero- 
1. Pulmonary arterial hypertension (PAH)

1.1 Idiopathic

1.2 Heritable

1.2.1 BMPR2

1.2.2 ALK1, endoglin (with or without hereditary hemorrhagic teleangiectasia)

1.2.3 Unknown

1.3 Drugs and toxins induced

1.4 Associated with (APAH):

1.4.1 Connective tissue diseases

1.4.2 HIV infection

1.4.3 Portal hypertension

1.4.4 Congenital heart disease

1.4.5 Schistosomiasis

1.4.6 Chronic haemolytic anemia

1.5 Persistent pulmonary hypertension of the newborn

1 ' Pulmonary veno-occlusive disease and/or pulmonary capillary haemangiomatosis

2. Pulmonary hypertension due to left heart disease

2.1 Sysytolic dysfunction

2.2 Diastolic dysfunction

2.3 Valvular disease

3. Pulmonary hypertension due to lung diseases and/or hypoxemia

3.1 Chronic obstructive pulmonary disease

3.2 Interstitial lung disease

3.3 Other pulmonary diseases with mixed restrictive and obstructive pattern

3.4 Sleep-disordered breathing

3.5 Alveolar hypoventilation disorders

3.6 Chronic exposure to high altitude

3.7 Developmental abnormalities

4. Chronic thromboembolic pulmonary hypertension

5. Pulmonary hypertension with unclear and/or multifactorial mechanisms

5.1 Hematological disorders: myeloproliferative disorders, splenectomy

5.2 Systemic disorders: sarcoidosis, pulmonary Langerhans cell histiocytosis, lymphangioleiomyomatosis, neurofibromatosis, vasculitis 5.3 Metabolic disorders: glycogen storage disease, Gaucher disease, thyroid disorders

5.4 Others: tumoral obstruction, fibrosing mediastinitis, chronic renal failure on dialysis

From [1].

sis, interstitial edema and lymphatic dilatation is found $[17,18]$. Pulmonary and mediastinal lymph nodes enlargement due to venous congestion and veno-lymphatic shunts has been described by Montpréville et al. [19].

In $\mathrm{PCH}$, capillary proliferation develops, either as the isolated pathology or, more frequently, as a reaction to increased venous pressure due to venous occlusion. Thus most pathologists use the name PVOD/PCH for such pathology $[17,18]$. Despite the occurrence of secondary pre-capillary arteriopathy in some PVOD/PCH cases, no complex lesions in pulmonary arteries are observed $[17,18]$.

Poor results of specific treatment may be also observed in PAH related to CTD [20-22]. Despite some recently reported therapeutic achievements in PAH-CTD [23-25], the results are worse than in IPAH. Dorfmuller et al. [26] described recently fibrous remodeling of the pulmonary venous system in PAH-CTD. This phenomenon may explain why these patients are less prone to respond to specific PAH treatment compared with IPAH. The authors suggest a clinically relevant hemodynamic effect of post-capillary occlusion in a setting of PAH-CTD, with PVOD-like pathology. PVOD-like pathology was described in PAH-CTD also by Overbeck et al. [27] and in the course of fatal granulomatous angiitis by Dwyer et al. [28].

The search for clinical markers of PVOD/PCH drew attention to the presence of lung pathology seen occasionally on CT scans in PAH.

\section{Value of lung CT scan in PAH}

In the majority of IPAH patients the only radiological abnormality seen on CT scans are the signs of pulmonary hypertension such as dilatation of pulmonary artery, pulmonary artery/aorta diameter $>1$ and right ventricular enlargement [29]. Nevertheless some investigators have noted the 
presence of mosaic attenuation on HRCT scans in IPAH patients.

Stern et al. [30] made an effort to categorize the diseases leading to mosaic pattern of lung attenuation. Three categories of lung disease are known to cause a mosaic pattern of lung attenuation on CT scan: small airways diseases, pulmonary vascular diseases and infiltrative lung diseases.

The mosaic pattern of lung attenuation caused by small airways diseases is a result of air trapping. This condition is recognized on $\mathrm{CT}$ scans obtained at full expiration. The mosaic pattern of lung attenuation caused by primary vascular disease is caused by regions of hyperemic lung (with higher attenuation) adjacent to oligemic regions of the lung (with lower attenuation). Mosaic attenuation due to vascular disease and due to small airways disease may produce a similar CT picture performed at inspiration with decrease of size and number of vessels in lucent parts of the lung compared with the regions with higher attenuation. Nevertheless no air trapping is seen on expiratory $\mathrm{CT}$ in the case of vascular disease.

The third cause of mosaic lung attenuation is an infiltrative lung disease, with areas of ground-glass attenuation due to interstitial or air space infiltrates, or both. In this condition no air trapping is seen on expiratory $\mathrm{CT}$ but the number and size of vessels in the areas of ground glass attenuation is similar to the areas of normal lung parenchyma.

The heterogeneity of perfusion in lung vascular pathology is most prominent in CTEPH due to the fact that the caliber of occluded vessels is greater than in PAH. So the areas of hypo- and hyper-perfusion are large enough to be seen on CT scans. This type of perfusion heterogeneity is called mosaic perfusion (Figure 1).

The heterogeneity of perfusion in PAH is less prominent than in CTEPH, due to the smaller caliber of

FIGURE 1: CHEST HRCT IMAGE FROM PATIENT WITH CHRONIC THROMBOEMBOLIC PULMONARY HYPERTENSION - MOSAIC PERFUSION

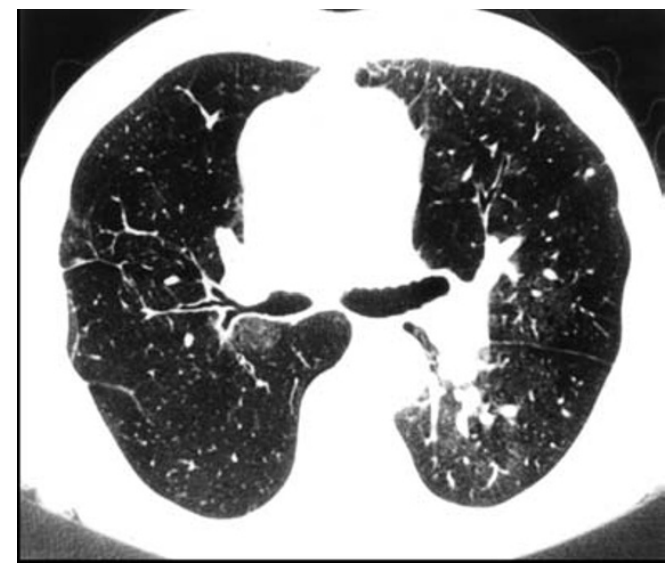

Definition of abbreviation: HRCT, high resolution computerized tomography. occluded vessels and more dispersed nature of the disease. Thus in the majority of PAH patients heterogeneity of lung perfusion is not seen. Nevertheless in some IPAH patients inhomogeneity of lung parenchyma is recognized but the mechanism involved in this pathology and the clinical significance of such finding is not clear.

Resten et al. [31] analyzed HRCT in $12 \mathrm{IPAH}$ patients with epoprostenol therapy failure (group 1) and compared them to 61 patients who improved during such therapy (group 2). Frequency of ground-glass opacities in groups 1 and 2 was, respectively, $83 \%$ and $38 \%$. The authors divided ground-glass opacities into two categories: class I poorly defined nodular opacities ranging in diameter from a few millimeters to 1 centimeter with centrilobular distribution, and class II - pan-lobular distribution of geographic regions of lung attenuation with relatively well defined borders. Class I opacities were found more frequently in group 1 than in group $2(61 \%$ and $21 \%$, respectively). The frequency of class II opacities was similar in both groups $(25 \%$ and $16 \%$ respectively). Thus only the presence of class I opacities correlated with the failure of epoprostenol therapy. The other parameters correlated with epoprostenol failure were: thickened interlobular septa, mediastinal lymphadenopathy and the presence of pericardial effusion. The results of post-mortem examination were available in 6 patients from group 1 and revealed the presence of $\mathrm{PVOD}$ or $\mathrm{PCH}$ in all of them. The authors concluded that the presence of poorly defined centrilobular opacities in combination with thickened septal lines, pleural or pericardial effusion and/or adenopathy in the patients with IPAH should raise a suspicion of PVOD or PCH.

The occurrence of centrilobular nodules in $25 \%$ of PAH patients was also described by Nolan et al. [32], who found the presence of cholesterol granulomas in them on pathologic examination. The mechanism of development of such granulomas could be related, according to the authors, to the degradation of excess of surfactant or to recurrent pulmonary hemorrhage. The nodules described by Nolan et al. [32] in PAH were an isolated finding, with no septal lines or lymphadenopathy.

In our own research [33], the retrospective analysis of HRCT scans revealed the presence of various forms of ground-glass opacities in 20 out of 48 (41\%) IPAH patients (Figure 2). According to their morphology they were divided into two groups: poorly defined centrilobular nodules (corresponding to the class I pathology of Resten et al.) - 17\% (Figure 2c) and focal ground-glass opacities with perihilar, peripheral or global localization (corresponding to the class II pathology of Resten et al.) $23 \%$ (Figure 2a,b). In the group of patients with centrilobular nodules, significantly higher mean right atrial pressure $(12.2 \pm 4.9 \mathrm{~mm} \mathrm{Hg}$ versus $7.6 \pm$ $5.3 \mathrm{~mm} \mathrm{Hg})$ and lower mean stroke volume $(41 \pm$ $8.5 \mathrm{ml}$ versus $58 \pm 18 \mathrm{ml}$ ) were found compared to the remaining IPAH patients. The presence of nodules was combined with poor prognosis (5-fold 
FIGURE 2: CHEST HRCT IMAGES FROM PATIENTS WITH IPAH (A-C). PATCHY (A) AND PERIHILAR (B) GROUND-GLASS OPACIFICATIONS; CENTRILOBULAR NODULES (C)

A
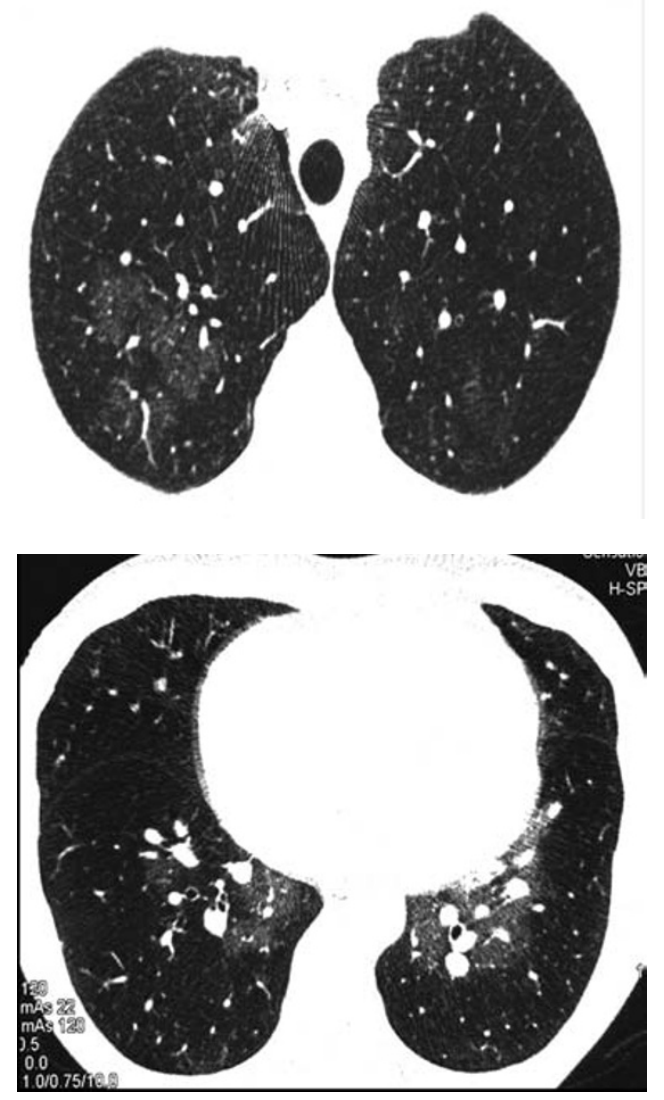

B

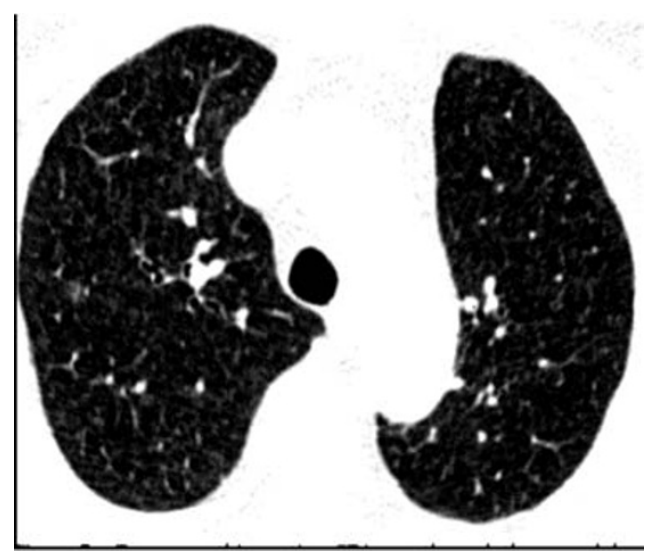

C

Definition of abbreviation: HRCT, high resolution computerized tomography.

higher risk of death compared to the remaining IPAH patients). Centrilobular nodules were found to be a strong independent poor prognostic indicator in our group of IPAH patients. It is not clear whether this population represented an underdiagnosed PVOD-like pathology or a distinct radiological IPAH pattern combined with poor prognosis.

No other features suggestive of PVOD were found in our material.
Radiological features of PVOD/PCH

$\mathrm{PVOD} / \mathrm{PCH}$ with the pathological changes seen in small venules and capillaries produces the radiological signs of pulmonary congestion and impaired lymphatic drainage. The typical radiological changes described on CT scans in PVOD represent the combination of septal lines, lymphadenopathy and pleural effusion. Many authors have also noted the presence of poorly defined centrilobular nodular opacities in PVOD.

Resten et al. [34] analyzed radiological features of pathologically confirmed PVOD in 15 patients and compared them with radiological features of 15 $\mathrm{PAH}$ patients. He found the presence of groundglass opacities in $87 \%$ of PVOD and in $33 \%$ of $\mathrm{PAH}$ $(p=0.003)$, septal lines in $93 \%$ of PVOD and $13 \%$ of PAH $(p<0.0001)$ and lymph nodes enlargement in $80 \%$ of PVOD and $0 \%$ of PAH ( $p<0.0001)$. The presence of pleural effusion, noted in $23 \%$ of PVOD and $13 \%$ of PAH, was not helpful in the differential diagnosis. The authors concluded that pleural effusion is a less specific sign of PVOD and should be regarded as characteristic only in the presence of other radiological PVOD features. This observation was confirmed by data reported by Tang et al. [35], who demonstrated pleural effusion in $25 \%$ of IPAH, mostly due to right heart failure. The patients with pleural effusion had significantly higher mean right atrial pressure (mRAP) than the remaining patients $(16.0 \pm 6.8 \mathrm{~mm} \mathrm{Hg}$ and $8.8 \pm$ $5.5 \mathrm{~mm} \mathrm{Hg}$ respectively). The majority of effusions were small and right sided.

The type of ground-glass opacities found by Resten et al. [34] was either centrilobular or pan-lobular. Centrilobular nodules were more characteristic of PVOD; nevertheless they appeared occasionally also in PAH.

It is not clear whether centrilobular nodules seen in PVOD represent a venopathy or alveolar consolidations due to lung congestion. Cassart et al. [36] described a complete resolution of ground-glass opacities in native lung 84 days after single lung transplantation in PVOD. This finding might support the theory of centrilobular nodules as a sign of pulmonary congestion in the presence of impaired outflow on the level of small pulmonary veins.

Dufour et al. [37] described small, centrilobular, poorly circumscribed nodular opacities in combination with thickening of interlobular septa in 2 patients with $\mathrm{PCH}$ and 2 patients with PVOD (biopsy proven). All these patients developed fatal pulmonary edema after treatment with intravenous epoprostenol.

The combination of centrilobular ground-glass opacities, septal lines and lymph nodes enlargement on lung CT scan had, according to Montani et al. [38], a $75 \%$ sensitivity and $85 \%$ specificity for detection of PVOD. Nevertheless the absence of such changes or the presence of only one radiological abnormality could not rule out PVOD.

El-Gabaly et al. [39] reported a case of PCH confirmed by open lung biopsy presenting on HRCT scans with numerous ill-defined centrilobular 


\begin{tabular}{|c|c|c|}
\hline & IPAH & PVOD \\
\hline Genetic mutations & BMPR2 mutations $10-40 \%$ & Cases of BMPR2 mutation \\
\hline \multicolumn{3}{|l|}{ Epidemiology } \\
\hline Sex & $\mathrm{F}: \mathrm{M}=2$ & $\mathrm{~F}: \mathrm{M}=1$ \\
\hline Tobacco exposure & Unrelated & More frequent than in IPAH \\
\hline Chemotherapy & Case reports & Case reports \\
\hline \multicolumn{3}{|l|}{ Clinical examination } \\
\hline Auscultatory crackles & No & Possible \\
\hline Clubbing & Possible & Possible \\
\hline Hemoptysis & Possible & Possible \\
\hline Pulmonary function tests & Normal (possible mild restrictive) & Normal (possible mild restrictive) \\
\hline $\mathrm{DL}_{\mathrm{co}}$ and $\mathrm{DL}_{\mathrm{co}} / \mathrm{VA}$ & Often reduced & Reduced, lower than IPAH \\
\hline $\mathrm{PaO}_{2}$ at rest & Often reduced & Reduced, lower than IPAH \\
\hline \multirow[t]{4}{*}{ HRCT } & Mild abnormalities & Frequent abnormalities: \\
\hline & & Centrilobular ground-glass opacities \\
\hline & & Septal lines \\
\hline & & Lymph node enlargement \\
\hline BAL & Normal & Possible occult alveolar hemorrhage \\
\hline Acute NO testing & $\begin{array}{l}\text { Positive: predictive of } \\
\text { CCB response and better } \\
\text { prognosis }\end{array}$ & $\begin{array}{l}\text { Not a predictor of } \mathrm{CCB} \text { response } \\
\text { (risk of pulmonary edema after initiation of } \mathrm{CCB} \text { ) }\end{array}$ \\
\hline Response to PAH therapy & $\begin{array}{l}\text { Improved hemodynamics, } \\
\text { functional status and outcome }\end{array}$ & $\begin{array}{l}\text { PVOD may deteriorate with a risk } \\
\text { of pulmonary edema }\end{array}$ \\
\hline
\end{tabular}

Definition of abbreviations: BAL, bronchoalveolar lavage; $C C B$, calcium channel blockers; $\mathrm{DL}$ co, diffusing lung capacity for carbon monoxide; $\mathrm{HRCT}$, high resolution computerized tomography; IPAH, idiopathic pulmonary arterial hypertension; $\mathrm{NO}$, nitric oxide; $\mathrm{PaO}_{2}$, partial pressure of arterial oxygen; $\mathrm{PAH}$, pulmonary arterial hypertension; $\mathrm{PVOD}$, pulmonary veno-occlusive disease; $\mathrm{VA}$, alveolar ventilation.

From [38] mod.

micronodular densities affecting both lungs, with no other radiological abnormalities. Isolated centrilobular ground-glass opacities were described recently by Iwaki et al. [40] in a 52-year-old female with biopsy-proven PVOD.

\section{Differential diagnosis of PVOD/PCH and IPAH}

Montani et al. [38] summarized clinical PVOD features that help to differentiate it from IPAH (Table II). They are: higher male/female ratio, higher tobacco exposure, lower arterial oxygen at rest, lower diffusing capacity for carbon monoxide and lower oxygen saturation nadir during 6MWT.

The other important feature of PVOD is the presence of occult alveolar hemorrhage. This observation was made by Rabiller et al. [41], who found in bronchoalveolar lavage a higher percentage of hemosiderin laden macrophages in PVOD compared to IPAH.

The reasons for a worse hypoxemia in PVOD than expected from PAP levels are: pulmonary edema, alveolar hemorrhage and overall more extensive obliteration of the pulmonary vascular bed. Montani et al. [38] found no significant differences in hemodynamic parameters between PVOD and IPAH. PCWP is not greater in PVOD compared to $\mathrm{IPAH}$, as it reflects the pressure in the pulmonary veins with a caliber similar to the pulmonary artery branch where the catheter is inserted and the occlusion maneuver performed, whilst the caliber of small veins and venules affected by PVOD is smaller.

Holcomb et al. [42] presented data concerning poor prognosis in PVOD: the 1-year mortality rate may be as high as $72 \%$. Montani et al. [38] found the mean time from diagnosis to death or lung transplant in PVOD to be $11.8 \pm 16$ months, which was significantly worse than in IPAH $(42.3 \pm 29.9$ months). The worse outcome of PVOD patients is probably related to the development of pulmonary edema either as part of the natural course of the disease or as precipitated by specific pulmonary vasodilator therapies. Due to the worse prognosis in PVOD patients and no evidence of effective pharmacotherapy, it is important to consider lung transplantation early in the course of the disease.

In summary, PVOD/PCH is a disease difficult to diagnose, in some cases presenting with a wide spectrum of radiologic abnormalities, but in many others indistinguishable from IPAH until the development of signs of pulmonary congestion in the course of treatment with vasodilators. The presence of ill-defined centrilobular nodules on lung HRCT scan in IPAH especially in combination with thick- 
ened septal lines and/or lymphadenopathy should draw attention to the possibility of a PVOD-like pathology. Targeted therapies should be applied with caution in such patients.

Lack of effect of targeted therapy should be a reason for early referral for lung transplantation.

CONFLICT OF INTEREST STATEMENT: None of the authors has any conflict of interest to declare in relation to the subject matter of this manuscript.

\section{References}

1. Proceedings of the $4^{\text {th }}$ World Symposium on Pulmonary Hypertension, February 2008, Dana Point, California, USA. J Am Coll Cardiol 2009;54(1 Suppl):S1-117.

2. ACCF/AHA 2009 expert consensus document on pulmonary hypertension: a report of the American College of Cardiology Foundation Task Force on Expert Consensus Documents and the American Heart Association: developed in collaboration with the American College of Chest Physicians, American Thoracic Society, Inc., and the Pulmonary Hypertension Association. Circulation 2009;119:2250-2294.

3. Hoeper MM. Definition, classification, and epidemiology of pulmonary arterial hypertension. Semin Respir Crit Care Med 2009;30:369-375.

4. Saggar R, Saggar R, Aboulhosn J, Belperio JA, Zisman DA, Lynch JP 3rd. Diagnosis and hemodynamic assessment of pulmonary arterial hypertension. Semin Respir Crit Care Med 2009;30:399-410.

5. Delcroix M, Corris PA. Pulmonary hypertension. Eur Respir Mon 2009;45:9-24.

6. Badesch DB, Abman SH, Simonneau G, Rubin LJ, McLaughlin VV. Medical therapy for pulmonary arterial hypertension: updated ACCP evidence-based clinical practice guidelines. Chest 2007;131:1917-1928.

7. Adamali H, Gaine SP, Rubin LJ. Medical treatment of pulmonary arterial hypertension. Semin Respir Crit Care Med 2009;30:484-492.

8. Benza RL, Park MH, Keogh A, Girgis RE. Management of pulmonary arterial hypertension with a focus on combination therapies. J Heart Lung Transplant 2007;26:437-446.

9. Fijałkowska A, Kurzyna M, Torbicki A, Szewczyk G, Florczyk M, Pruszczyk P, Szturmowicz M. Serum N-terminal brain natriuretic peptide as a prognostic parameter in patients with pulmonary hypertension. Chest 2006;129:1313-1321.

10. Torbicki A, Kurzyna M, Kuca P, Fijałkowska A, Sikora J, Florczyk M, Pruszczyk P, Burakowski J, Wawrzyńska L. Detectable serum cardiac troponin $\mathrm{T}$ as a marker of poor prognosis among patients with chronic precapillary pulmonary hypertension. Circulation 2003;108:844-848.

11. Rafeq S, Shah AM, Preston IR. Biomarkers in pulmonary arterial hypertension. Int J Clin Pract Suppl 2009;63(suppl 162):36-41..

12. Galiè N, Manes A, Negro L, Palazzini M, Bacchi-Reggiani $\mathrm{ML}$, Branzi A. A meta-analysis of randomized controlled trials in pulmonary arterial hypertension. Eur Heart J 2009;30:394-403.

13. Harch S, Whitford H, McLean C. Failure of medical therapy in pulmonary arterial hypertension. Is there an alternative diagnosis? Chest 2009;135:1462-1469.

14. Montani D, Achouh L, Dorfmuller P, Le Pavec J, Sztrymf B, Tchérakian C, Rabiller A, Haque $R$, Sitbon $O$, Jaïs $X$, Dartevelle P, Maître S, Capron F, Musset D, Simonneau G, Humbert M. Pulmonary veno-occlusive disease: clinical, functional, radiologic, and hemodynamic characteristics and outcome of 24 cases confirmed by histology. Medicine (Baltimore) 2008;87:220-233.

15. Wahidi MM, Rocha AT, Hollingsworth JW, Govert JA, Feller-
Kopman D, Ernst A. Contraindications and safety of transbronchial lung biopsy via flexible bronchoscopy. A survey of pulmonologists and review of the literature. Respiration 2005;72:285-295.

16. Frazier AA, Franks TJ, Mohammed TL, Ozbudak IH, Galvin JR. From the Archives of the AFIP: pulmonary veno-occlusive disease and pulmonary capillary hemangiomatosis. Radiographics 2007;27:867-882.

17. Lantuéjoul S, Sheppard MN, Corrin B, Burke MM, Nicholson AG. Pulmonary veno-occlusive disease and pulmonary capillary hemangiomatosis: a clinicopathological study of 35 cases. Am J Surg Pathol 2006;30:850-857.

18. Pietra GG, Capron F, Stewart S, Leone O, Humbert M, Robbins IM, Reid LM, Tuder RM. Pathologic assessment of vasculopathies in pulmonary hypertension. J Am Coll Cardiol 2004;43(12 suppl S):25S-32S.

19. Thomas de Montpréville V, Dulmet E, Fadel E, Dartevelle P. Lymph node pathology in pulmonary veno-occlusive disease and pulmonary capillary hemangiomatosis. Virchows Arch 2008;453:171-176.

20. Condliffe R, Kiely DG, Peacock AJ, Corris PA, Gibbs JS, Vrapi F, Das C, Elliot CA, Johnson M, DeSoyza J, Torpy C, Goldsmith K, Hodgkins D, Hughes RJ, Pepke-Zaba J, Coghlan JG. Connective tissue disease-associated pulmonary arterial hypertension in the modern treatment era. Am J Respir Crit Care Med 2009;179:151-157.

21. Hachulla E, Launay D, Yaici A, Berezne A, de Groote $P$, Sitbon O, Mouthon L, Guillevin L, Hatron PY, Simonneau G, Clerson P, Humbert M; French PAH-SSc Network. Pulmonary arterial hypertension associated with systemic sclerosis in patients with functional class II dyspnoea: mild symptoms but severe outcome. Rheumatology (Oxford) 2010;49:940-944.

22. Hassoun PM. Therapies for scleroderma-related pulmonary arterial hypertension. Expert Rev Respir Med 2009;3:187-196.

23. Williams MH, Das C, Handler CE, Akram MR, Davar J, Denton CP, Smith CJ, Black CM, Coghlan JG. Systemic sclerosis associated pulmonary hypertension: improved survival in the current era. Heart 2006;92;926-932.

24. Badesch DB, McGoon MD, Barst RJ, Tapson VF, Rubin LJ, Wigley FM, Kral KM, Raphiou IH, Crater GD. Longterm survival among patients with scleroderma-associated pulmonary arterial hypertension treated with intravenous epoprostenol. J Rheumatol 2009;36:2244-2249.

25. Keogh AM, McNeil KD, Wlodarczyk J, Gabbay E, Williams TJ. Quality of life in pulmonary arterial hypertension: improvement and maintenance with bosentan. J Heart Lung Transplant 2007;26:181-187.

26. Dorfmüller $P$, Humbert M, Perros F, Sanchez O, Simonneau G, Müller KM, Capron F. Fibrous remodeling of pulmonary venous system in pulmonary arterial hypertension associated with connective tissue diseases. Hum Pathol 2007;38:893-902.

27. Overbeek MJ, Vonk MC, Boonstra A, Voskuyl AE, VonkNoordegraaf A, Smit EF, Dijkmans BA, Postmus PE, Mooi WJ, Heijdra Y, Grünberg K. Pulmonary arterial hypertension in limited cutaneous sclerosis: a distinctive vasculopathy. Eur Respir J 2009;34:371-379. 
28. Dwyer N, Smith R, Challis D, Reid D, Kilpatrick D. Granulomatous angiitis leading to a pulmonary veno-occlusive disease-like picture. Eur Respir J 2009;33:666-669.

29. Burakowska B, Pawlicka L, Oniszh K, Burakowski J, Kurzyna M, Kober J, Fijałkowska A, Hajduk B, Tomkowski W, Bestry I, Torbicki A. Value of spiral computed tomography in pulmonary hypertension. Pol Arch Med Wewn 2004;111:431-441.

30. Stern EJ, Müller NL, Swensen SJ, Hartman TE. CT mosaic pattern of lung attenuation: etiologies and terminology. J Thorac Imaging 1995;10:294-297.

31. Resten A, Maitre S, Humbert M, Sitbon O, Capron F, Simoneau G, Musset D. Pulmonary arterial hypertension: thin-section $\mathrm{CT}$ predictors of epoprostenol therapy failure. Radiology 2002;222:782-788.

32. Nolan RL, McAdams HP, Sporn TA, Roggli VL, Tapson VF, Goodman PC. Pulmonary cholesterol granulomas in patients with pulmonary artery hypertension: chest radiographic and CT findings. AJR Am J Roentgenol 1999;172:1317-1319.

33. Kacprzak A, Szturmowicz M, Burakowska B, Fijałkowska A, Kurzyna $M$, Wieteska $M$, Florczyk $M$, Zyłkowska J, Franczuk M, Wesołowski S, Torbicki A. Abnormalities in high-resolution computed tomography of the lungs in patients with idiopathic pulmonary arterial hypertension correlation with hemodynamic parameters and prognostic significance. Pneumonol Alergol Pol 2009;77:23-30.

34. Resten A, Maitre S, Humbert M, Rabiller A, Sitbon O, Capron F, Simonneau G, Musset D. Pulmonary hypertension: $\mathrm{CT}$ of the chest in pulmonary venoocclusive disease.
AJR Am J Roentgenol 2004;183:65-70.

35. Tang KJ, Robbins IM, Light RW. Incidence of pleural effusions in idiopathic and familial pulmonary arterial hypertension patients. Chest 2009;136:688-693.

36. Cassart M, Gevenois PA, Kramer $M$, Jacobovitz D, de Francquen P, Yernault JC, Estenne M. Pulmonary venoocclusive disease: CT findings before and after single-lung transplantation. AJR Am J Roentgenol 1993;160:759-760.

37. Dufour B, Maître S, Humbert M, Capron F, Simonneau G, Musset D. High-resolution CT of the chest in four patients with pulmonary capillary hemangiomatosis or pulmonary venoocclusive disease. AJR Am J Roentgenol 1998;171: 1321-1324.

38. Montani D, Price LC, Dorfmuller P, Achouh L, Jaïs X, Yaïci A, Sitbon O, Musset D, Simonneau G, Humbert $M$. Pulmonary veno-occlusive disease. Eur Respir J 2009;33:189-200.

39. El-Gabaly M, Farver CF, Budev MA, Mohammed TL. Pulmonary capillary hemangiomatosis imaging findings and literature update. J Comput Assist Tomogr 2007;31:608-610.

40. Iwaki $M$, Imaizumi $K$, Yokoi T, Kondo $M$, Kawaguchi $K$, Hasegawa Y. Idiopathic pulmonary veno-occlusive disease. Inter Med 2009;48:1289-1292.

41. Rabiller A, Jaïs X, Hamid A, Resten A, Parent F, Haque R, Capron F, Sitbon O, Simonneau G, Humbert M. Occult alveolar haemorrhage in pulmonary veno-occlusive disease. Eur Respir J 2006;27:108-113.

42. Holcomb BW Jr, Loyd JE, Ely EW, Johnson J, Robbins IM. Pulmonary veno-occlusive disease: a case series and new observations. Chest 2000;118:1671-1679. 